\title{
Glandular Odontogenic Cysts in Maxilla: Literature Review and Report on Cases
}

\section{Mahrokh Imanimoghaddam, Soraya Bakhshani*, Adineh Javadian Langeroodi}

Department of Oral and Maxillofacial Radiology, School of Dentistry, Mashhad University of Medical Sciences, Mashhad,Iran

Study Area: Mashhad, Iran

Coordinates: $36^{\circ} 18^{\prime} \mathrm{N} ; 59^{\circ} 36^{\prime} \mathrm{E}$

Key words: Apparent diffusion coefficient map, MR imaging.

\section{Abstract}

Glandular odontogenic cysts are rare developmental lesions affecting the mandible, especially its anterior region, more frequently seen in males. This cyst has a high recurrence rate and its radiographic image is associated with its rate of recurrence. There is some overlap between features of radiographic and histopathological images of glandular odontogenic cysts and those of some lesions such as mucoepidermoid carcinoma. Moreover, diagnosis of this cyst is very important due to its invasive potential. This article is based on two patients reported with glandular odontogenic cysts in the maxilla, which is an uncommon location for this lesion. The first patient was a male,63-yrs. with a glandular odontogenic cyst in the maxillary anterior region. The second reported patient was a female, 21 yrs. where lesion observed in the maxillary posterior region.

maxillary posterior region of a female patient.

\section{Observed cases:}

\section{Case-1:}

Patient is of 63 yrs. man who became aware of a swelling under his denture in the maxillary anterior region adjacent to midline on the right side a year ago. He maintained the swelling was drained when the denture experienced pressure, oozing a blood-like liquid. However, since last month, a new swelling has been formed once again in the same region under the denture. According to the patient, he was not having any notable medical history. The mucosa on the swelling was normal and of the same colour as the adjacent mucosa (Fig.-1). In the complete image taken, a single well-demarcated lucent lesion with a cortical border was observed in the maxillary anterior region near the midline area on the right side (Fig.-2).

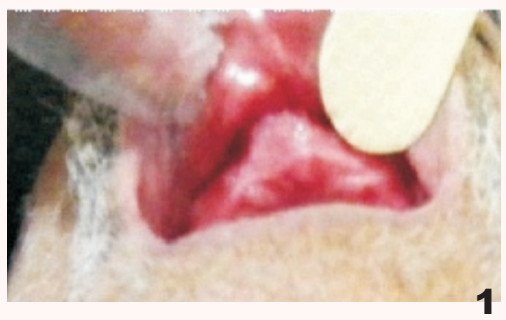

Figure-1: Cyst-like swelling in the maxillary anterior region on the right side adjacent to the midline

A "Cone Beam Computed Tomography" (CBCT) examination was performed to study the effects of the cyst 9), this article aims to report two cases of GOC in maxillary anterior region of a male patient and in the 


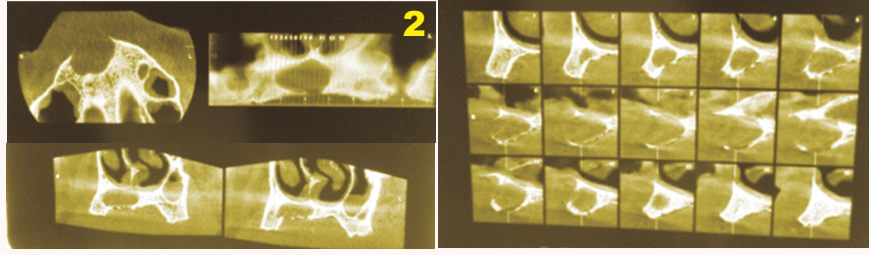

Figure-2: The lucent region with cortical borders in the maxillary anterior region

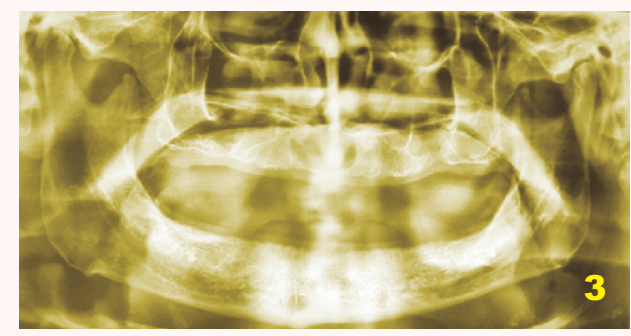

Figure-3: CBCT image. Destruction of the cortical bone on the palatal side and erosion of the cortical bone on the buccal side

on the nasopalatine canal (Fig.-3). The prepared CBCT image showed erosion of the palatal wall and destruction of the buccal wall. Since the wall of the nasopalatine canal was observed on CBCT cross-sectional images, the probability of the cyst being a nasopalatine canal cyst was ruled out. The differential diagnoses that were considered for this lesion included residual cyst, odontogenic keratocyst, "Calcifying Odontogenic Cyst" (COC), and central giant cell granuloma. The patient was referred to the surgical ward for a biopsy procedure.

Histopathological examination of the prepared sample showed a developmental odontogenic cyst. The inner surface of the cyst was made of stratified squamous epithelium, but parts of it consisted of ciliated cylindrical epithelium, mucous cells, and glandular areas could be seen in-between the epithelial cells. The juncture of the epithelium with the connective tissue was smooth and the connective chorion of the cyst contained collagen fibers. Inflammatory infiltration of lymphoplasmacytic cells was observed at the depth of the lesion in the cross-sections of the striated muscles and nerves. The lesion was diagnosed as a developmental odontogenic cyst of the glandular odontogenic type.

\section{Case-2:}

Patient was a 21 yrs. female with a swelling in the palatal area of the maxillary posterior region who referred to the Mashhad School of Dentistry (Fig.-4). The swelling developed one year back. Vitality tests of the teeth in the region were positive. In the periapical image, on the right side of the first molar region, the periodontal ligament was slightly loose (Fig.-5). In the complete image, a welldemarcated radiolucency was observed in the maxillary posterior region from the apex of the first premolar to the distal of the first molar (Fig.-6). Possible diagnoses for this patient included odontogenic Keratocyst and Calcifying Odontogenic Cyst (COC).
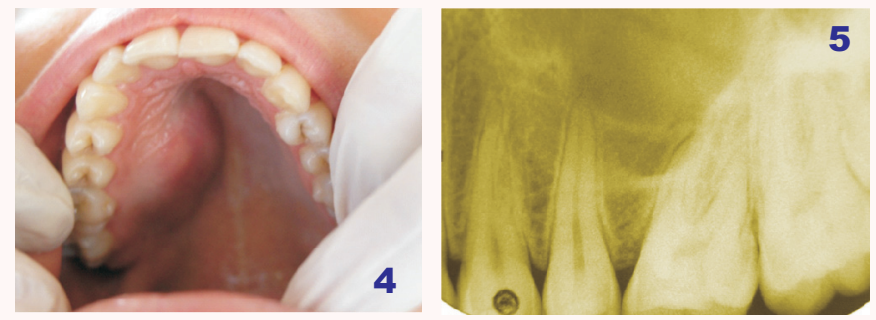

Figure-4: Clinical view- swelling in the palatal area of the maxillary posterior region on the right side.

Figure 5: Periapical view: well-demarcated radiolucency of the apices of teeth 4-6 showing increased PDL width.

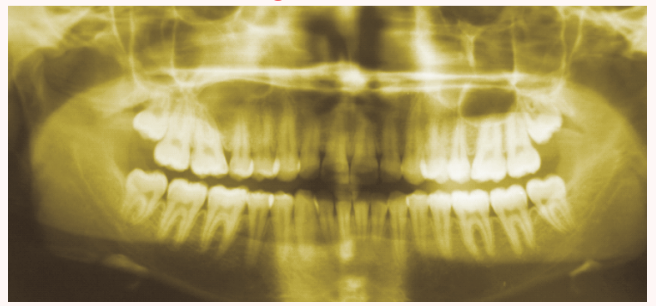

Figure 6: 2nd patient: noncortical well-demarcated radiolucency from the distal tooth 4 to the distal tooth 6

The histopathological examination included an incomplete excision of the cystic wall that consisted of 2-6 layers of stratified squamous epithelium together with a number of mucous cells and mucin-containing pools. The stroma of the cyst consisted of fibrovascular connective tissue, and inflammatory infiltration of lymphoplasmacytic cells was observed. Sections of adipose tissue, vessels, nerves and of the minor salivary glands were obtained from a part of the sample. Based on pathological and radiographic findings, the final diagnosis was that the cyst was of the glandular odontogenic type.

\section{Discussion:}

GOC is evidenced as a rare lesion that accounts for 0.02 to 1.2 percent for all jaw lesions (Manor et al., 2003). There were no reports of GOC until Padayachee \& Van Wyk (1987) who reported the first GOC lesion (MacdonaldJankowski, 2010). In a study conducted by Sharifian \& Khalili (2007) on odontogenic cysts among 1,277 Iranian patients from 1987 to 2007 , GOC was found in about 0.3 percent of the total cases of jaw cysts. How far the gender is concerned, the GOC is more prevalent among men in all age decades but, in women, it is more common in the $\mathrm{fifth}$ age decade, which is the general peak decade for GOC. This anomaly may reflect hormonal changes in women during the perimenopausal period (Macdonald-Jankowski, 2010). However, higher prevalence has been reported in women in some references (Tran et al., 2004).

The second patient mentioned in this article was a 21 yrs. female. In a study by Khosravi et al. (2013) conducted in Isfahan on demographic distribution of odontogenic cysts, 85 percent of the GOC cases were observed in women and only 14.29 percent in men and the average age of the patients was 50. However, report of Sharifian \& Khalili 
(2007) evidenced for equal numbers of male and female patients. A large percentage of patients reported in the study by Macdonald-Jankowski (2010) were in the second half of their $\mathrm{fifth}$ age decade, but the target groups were of lower age decades in East Asia and the Sahara Desert. According to a study by Kaplan et al. (2008) GOC was observed in the age range of 14-75 year. However, Faisal et al., (2015) reported a GOC case in the mandible of an 11year-old youngster. Our first and second patients were, respectively, of higher and lower age than the peak age for glandular odontogenic cyst development.

As per White \& Pharoah (2014) Glandular odontogenic cysts are more prevalent in the anterior region. In the West (North America and Europe), GOC is reported to be more inclined to affect the anterior regions of both jaws (Macdonald-Jankowski, 2010). In a study by Khosravi et al., (2013) 28.57 percent of GOC lesions were seen in the maxillary anterior region and 14.20 percent in the maxillary posterior region. Although GOC is formed in the mandible four times more compared to the maxilla (Padayachee \& Van Wyk, 1987), yet it was observed in the maxilla of both of our patients (in the first patient in the maxillary anterior edentulous region, and in the second patient in the maxillary posterior region).

As for shape and border, 53 percent of the lesions were also seen to be unilocular (Tran et al., 2004). The rate of multilocular lesions in GOC was seen higher compared to other odontogenic cysts (Manor et al., 2003). In 95 percent of the patients the border was reported to be well-def ined (Kaplan et al., 2008), with reported sclerotic margins (Manor et al., 2003) and scalloped edges (Kaplan et al., 2008) observed in merely 7.7 and 13 percent of the cases, respectively. In both of our patients, the lesions were unilocularwith well-def ined cortical borders.

The case report reviews revealed that most lesions in male patients developed exclusively in the maxillary anterior region, were unilocular, where the patients were younger than 40 years of age (Manor et al., 2003; Noffke \& Raubenheimer, 2002; Mascitti et al., 2014; Kim et al., 2012; Bhat et al., 2014). In our representative first patient, the lesion was unilocular but he was 63 yrs. Koppang et al., (1998) reported a lesion in the maxillary anterior region of a 69-yrs. man. Further, Patron et al. (1991) reviewed the case of a 52 yrs. patient who had been treated for unilocular ameloblastoma of the maxillary anterior region, and reintroduced it as a glandular odontogenic cyst.

Lesions vary in size from 0.5 to $2 \mathrm{~cm}$ (Kaplan et al., 2008). One type of size classification for GOC is based on the number of affected teeth: if more than two teeth are affected, the GOC is considered large, but it is considered small if fewer than two teeth are affected (Kaplan et al., 2005). Based on this classification system, the ratio of large to small lesions is four to one ( 76 percent of the lesions are large) (Kaplan et al., 2008). In the study carried out by Marco, 7.3 percent of the lesions had affected the anterior and posterior regions simultaneously (Mascitti et al., 2014). In our first patient, the lesion was confined to the anterior region.

Based on previous studies, most patients suffer from painless swellings (Sittitavornwong et al., 2006). Our both the patients had painless swellings. Multilocular lesions have a greater inclination for cortical expansion. In 61 percent of the cases, GOC is accompanied by perforation of the cortical bone and in 24 percent of the cases by cortical bonethinning (Kaplan et al., 2008).

It has been reported that GOC is accompanied by odontogenic keratocyst and ameloblastoma (Yoon et al., 2006; Hisatomi et al., 2000; Kasaboglu et al., 2006; Geist et al., 2004) as well as by impacted teeth.

Lesion size is related to the rate of recurrence where about 86 percent of cases of recurrence are related to large lesions. The GOC may recur more than once, and lesions that cause perforation are more likely to recur and are often multilocular (Kaplan et al., 2008). Recurrence may occur even after seven years, and a minimum follow-up period is of three years which usually extends for longer than seven years, i.e., a high risk of recurrence (Kaplan et al., 2005). Thro et al. (2006) followed up the cases of 13 patients with GOC and noticed recurrence in 11 of them during the first ten years. Manor et al. (2003) studied complete radiography, the first conventional radiography for GOC, and prepared CT specimen to study perforation in five patients. They suggested CT be performed for large lesions, especially multilocular lesions and/or lesions that affect structures outside of the jaws such as the sinuses and the nasal floor or orbit. Some studies have shown discrepancies between diagnoses based on conventional radiography and those based on CT, but Cano et al. (2012) reported there were no differences between these two. Oliveira et al. (2009) stated in their article that, in conventional radiography, the image of the patient's lesion was observed as unilocular radiolucency, but CT scan of the patient showed a multilocular lesion with cortex perforation. Hisatomi et al. (200o) stated a wide range of imaging modalities such as MRI were helpful in GOC accompanied byameloblastoma.

In our first patient, complete radiography was first employed. CBCT was then used to study perforation of the nasal floor and cortex. The lesion was unilocular both in the complete and the CBCT images, but perforation was observed in the latter.

Clinically and pathologically, GOC varies from a small benign pathologic lesion to a destructive malignant neoplasm such as a central mucoepidermoid carcinoma (Kasaboglu et al., 2006). Some researchers believe this cyst cannot be diagnosed because its histological image overlaps those of other odontogenic cysts such as botryoid and/or lateral odontogenic cysts and low-grade mucoepidermoid carcinoma (Manor et al., 2003; Sittitavornwong et al., 2006). In both of our patients, 
odontogenic keratocyst was considered one of the possible diagnoses. Moreover, giant cell granuloma was similar to the glandular odontogenic cyst (Tran et al., 2004). Hisatomi et al. (2003) stated in their study that MRI could not distinguish GOC from dentigerous, radicular, and nasopalatine cysts.

GOC is an odontogenic cyst and must be distinguished from nasopalatine cysts, which are fissural cysts (Kim et al., 2012). For our first patient, who had a lesion in the maxillary anterior region, we employed the $\mathrm{CBCT}$ technique to distinguish the GOC from a possible nasopalatine cyst. It was revealed that the cyst was not a nasopalatine one because the canal wall had not been destroyed.

The GOC is treated by curettage or enucleation, although some researchers prefer marginal resection to prevent recurrence inclination after curettage or enucleation (Kasaboglu et al.., 2006). Based on the radiography images, the differential diagnoses considered for the first patient included residual cyst (related to an infected tooth that had been extracted earlier), odontogenic keratocyst, calcifying odontogenic cyst $(\mathrm{COC})$, and central giant cell granuloma (based on the lesion's location and shape). The differential diagnoses considered for the second patient, who had a lesion in the maxillary posterior region, were odontogenic keratocyst and calcifying odontogenic cyst. Due to the similarities in histopathological images and invasive potential, and because of the high recurrence rate of glandular odontogenic cysts, especially in the first patient in whom perforation had also happened, it is necessary to diagnose the cyst correctly, treat it appropriately and employ followup procedures for the patient in a regular manner.

\section{Conclusions:}

Due to the invasive potential and high recurrence rate of the glandular odontogenic cyst, and because of its great similarities to other jaw cysts, it must be correctly diagnosed, adequately treated, and regularly followed up for severalyears..

\section{Acknowledgment:}

The authors are thankful to the subjects (two patients) who had allowed us to use their medical data as a part of this report.

\section{References:}

Anchlia, S., Bahl, S., Shah, V., Vyas, S. (2015): Glandular odontogenic cyst: a rare entity revealed and a review of the literature. BMJ case reports. , Epub 2015/o8/25.

Bhat, K.K., Shetty, P., Adyanthaya, A. \& Adyanthaya, S. (2014): The Glandular Odontogenic Cyst of the Anterior Maxilla: Report of Two Cases. Malay. Dent. J., 36(2):15-19.

Cano, J., Benito, D.M., Montans, J., Rodriguez-Vazquez, J.F., Campo, J. \& Colmenero, C. (2012): Glandular odontogenic cyst: two high-risk cases treated with conservative approaches. J.Cranio-maxillo-facialSurg., 40(5):e131-6.
Faisal, M., Ahmad, S.A. \& Ansari, U. (2015): Glandular odontogenic cyst - Literature review and report of a paediatric case. J. Oral Biol. Craniofac. Res., 5(3):219-25.

Geist, J., Gordon, S. \& Wesley, R. (2003): Oral pathology quiz: an unusual pericoronal cyst. The diagnosis was glandular odontogenic cyst, although focal areas consistent with dentigerous cyst were seen. J. Mich. Dent. Assoc., 85(12):40.

Hisatomi, M., Asaumi, J., Konouchi, H., Yanagi, Y. \& Kishi, K. (2000): A case of glandular odontogenic cyst associated with ameloblastoma: correlation of diagnostic imaging with histopathological features. Dentomaxillofac. Radiol., 29(4):249-253.

Hisatomi, M., Asaumi, J., Konouchi, H., Shigehara, H., Yanagi, Y. \& Kishi, K. (2003): MR imaging of epithelial cysts of the oral and maxillofacial region. Eur. J. Radiol.,48(2):178-182.

Kaplan, I., Gal, G., Anavi, Y., Manor, R. \& Calderon, S. (2005): Glandular odontogenic cyst: treatment and recurrence. I. Oral Maxillofac. Surg. 63(4):435-441.

Kaplan, I., Anavi, Y. \& Hirshberg, A. (2008): Glandular odontogenic cyst: a challenge in diagnosis and treatment. Oral Dis. , 14(7):575-581.

Kasaboglu, O., Basal, Z. \& Usubutun, A. (2006): Glandular odontogenic cyst presenting as a dentigerous cyst: a case report.J. Oral Maxillofac. Surg., 64(4):731-733.

Khosravi, N., Razavi, S.M., Kowkabi, M. \& Navabi, A.A. (2013): Demographic distribution of odontogenic cysts in Isfahan (Iran) over a 23-year period (1988-2010). Dent. Res. L.10(2):162-167.

Kim, Y., Song, E.R. \& Lee, S.K. (2012): Differential Diagnosis of Glandular Odontogenic Cyst Versus non-odontogenic cyst in anterior maxilla. Kor. J. Oral Maxillofac. Pathol. 36(2):113-120.

Koppang, H.S., Johannessen, S., Haugen, L.K., Haanaes, H.R., Solheim, T. \& Donath, K. (1998): Glandular odontogenic cyst (sialo-odontogenic cyst): report of two cases and literature review of 45 previously reported cases. L. Oral Pathol. Med., $.27(9): 455-462$.

Kramer, I.R., Pindborg, J.J. \& Shear, M. (1992): The WHO Histological Typing of Odontogenic Tumours. A commentary on theSecond Edition. Cancer.,70(12):2988-2994.

Krishnamurthy, A., Sherlin, H.J., Ramalingam, K., Natesan, A., Premkumar, P., Ramani, P., \& Chandrasekar, T. (2009): Glandular odontogenic cyst: report of two cases and review of literature. Head Neck Pathol., 3(2):153-158.

Lyrio, M.C., de Assis, A.F., Germano, A.R. \& de Moraes, M. (2010): Treatment of mandibular glandular odontogenic cyst with immediate reconstruction: case report and 5-year follow-up. BritishJOral Maxillofac. Surg., 48(8):651-653.

Macdonald-Jankowski, D.S. (2010): Glandular odontogenic cyst: systematic review. Dentomaxillofac. Radiol., 39(3):127-139.

Manor, R., Anavi, Y., Kaplan, I. \& Calderon, S. (2003): Radiological features of glandular odontogenic cyst. Dentomaxillofac. Radiol.,32(2):73-79.

Mascitti, M., Santarelli, A., Sabatucci, A., Procaccini, M., Lo Muzio, L., Zizzi, A., \& Rubini C. (2014): Glandular odontogenic cyst: review of literature and report of a new case with cytokeratin-19 expression. Open Dent. J., 8:1-12. 
REVIEW ARTICLE

Neville, B.W., Damm, D.D.,ý Allen, C.Mý. \& Bouquot, J.E. (2008). Oral and Maxillofacial Pathology, zrd Edition. Pub. By: Saunders; 3 rd edition; p. 984

Noffke, C. \& Raubenheimer, E.J. (2002): The glandular odontogenic cyst: clinical and radiological features; review of the literature and report of nine cases. Dentomaxillofac Radiol., 31(6):333-338.

Oliveira, J.X., Santos, K.C., Nunes, F.D., Hiraki, K.R., Sales, M.A., Cavalcanti, M.G., \& Marcucci, M. (2009): Odontogenic glandular cyst: a case report. J. Oral Sci., 51(3):467-470.

Padayachee, A \& Van Wyk, C.W. (1987): Two cystic lesions with features of both the botryoid odontogenic cyst and the central mucoepidermoid tumour: sialo-odontogenic cyst? L Oral Pathol., 16(10):499-504.

Patron, M., Colmenero, C. \& Larrauri, J. (1991): Glandular odontogenic cyst: clinicopathologic analysis of three cases. OralSurg. Oral Med. Oral Pathol., 72(1):71-74.

Sharifian, M.J. \& Khalili, M. (2011): Odontogenic cysts: a retrospective study of 1227 cases in an Iranian population from 1987 to 2007. J. OralSci., 53(3):361-367.
Ambient Science, 2018: Vol. 05(Sp1); 11-15 DOI:10.21276/ambi.2018.05.sp1.rv01

Sittitavornwong, S., Koehler, J.R. \& Said-Al-Naief, N. (2006): Glandular odontogenic cyst of the anterior maxilla: case report and review of the literature. L. Oral Maxillofac. Surg. 64(4):740-745.

Thor, A., Warfvinge, G. \& Fernandes, R. (2006): The course of a long-standing glandular odontogenic cyst: marginal resection and reconstruction with particulated bone graft, platelet-rich plasma, and additional vertical alveolar distraction.J. Oral Maxillofac. Surg., 64(7):1121-1128.

Tran, P.T., Cunningham, C.J. \& Baughman, R.A. (2004): Glandular odontogenic cyst. J.Eendodont., 30(3):182-184.

Salehinejad, J., Saghafi, S., Zare-Mahmoodabadi, R., Ghazi, N. \& Kermani, H. (2011): Glandular odontogenic cyst of the posterior maxilla. Arch. Iran. Med., 14(6):416-418.

White, S.C. \& Pharoah, M.J. (2014): Oral radiology principles and interperetation. Pub by.: Elsevier. P. 696.

Yoon, J.H., Ahn, S.G., Kim, S.G. \& Kim, J. (2006): An unusual odontogenic cyst with diverse histologic features. Yonsei Med.J., 47(1):122-125.

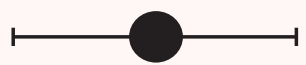

